\title{
The Effect of Rotary Degassing Treatments with Different Purging Gases on the Double Oxide- and Nitride Film Content of Liquid Aluminum Alloys
}

\author{
GÁBOR GYARMATI (®), FANNI VINCZE, GYÖRGY FEGYVERNEKI (1), \\ ZOLTÁN KÉRI, TAMÁS MENDE (D), and DÁNIEL MOLNÁR
}

Rotary degassing is one of the most frequently used melt treatment technologies used for processing liquid aluminum alloys. Despite this, the information available about the possible effects of this method on the double oxide- and nitride film (bifilm) content, especially when using different purging gases, is quite limited. For this reason, in this study, the effects of multiple rotary degassing treatments conducted with $\mathrm{N}_{2}$ and Ar purging gases on the bifilm quantity of a casting aluminum alloy were compared. The characterization of the melt quality was realized by the computed tomographic (CT) analysis of reduced pressure test (RPT) specimens, image analysis, and scanning electron microscopy (SEM) of the fracture surfaces of K-mold samples. Based on the results, by the application of Ar as a purging gas, relatively low bifilm content can be achieved. On the other hand, while the use of $\mathrm{N}_{2}$ leads to the formation of numerous small-sized nitride bifilms, which significantly increased the pore number density inside the RPT specimens. This can be associated with the nitride formation by the chemical reaction between the liquid aluminum alloy and the $\mathrm{N}_{2}$ purging gas bubbles during the degassing treatments.

\section{Graphical abstract}

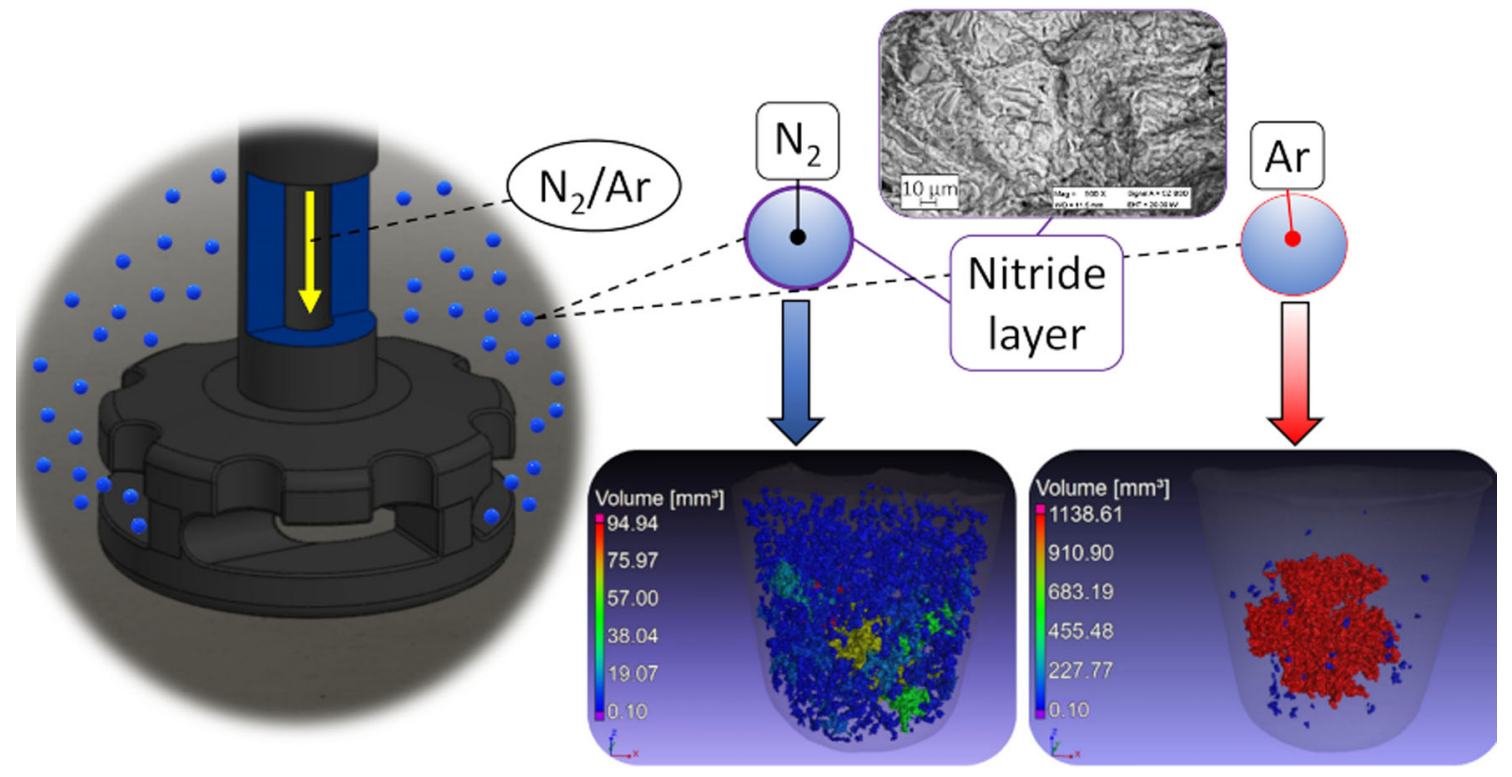

https://doi.org/10.1007/s11663-021-02414-0

(C) The Author(s) 2022

GÁBOR GYARMATI, FANNI VINCZE, GYÖRGY FEGYVERNEKI, ZOLTÁN KÉRI, and DÁNIEL MOLNÁR are with the Foundry Institute, University of Miskolc, MiskolcEgyetemváros, 3515 Hungary. Contact e-mails: ontgabor@unimiskolc.hu; gygabor007@gmail.com TAMÁS MENDE is with the Institute of Physical Metallurgy, Metalforming and Nanotechnology, University of Miskolc, Miskolc-Egyetemváros, 3515 Hungary.

Manuscript submitted October 7, 2021, accepted December 12, 2021.

Article published online January 17, 2022.

\section{INTRODUCTION}

DURING the manufacturing of aluminum alloy castings, one of the key parameters which can determine the ability of a cast part to meet the industrial requirements is the quality of the liquid metal used during the casting process. $^{[1]}$ For a given alloy 
composition (including the concentrations of metallic impurity elements), the main contributors to the deterioration of melt quality are the double oxide and/or nitride film defects (bifilms) and the solute hydrogen content. ${ }^{[2]}$ In most cases, processing metals in the liquid state inevitably creates favorable conditions for bifilm formation. Bifilms are the most common metallurgical defects of aluminum alloys, as they are easily created during common industrial activities like melting, melt transporting, alloying, melt treatments, and the casting process itself. ${ }^{[3-5]}$ Besides their obvious negative effect on the mechanical properties, there is a growing body of literature that suggests that bifilms dominantly influence the occurrence of defects like porosity ${ }^{[6-10]}$ and hot tears. ${ }^{[10-12]}$ It was also hypothesized that the presence of bifilms has a remarkable effect on the heterogeneous nucleation of various intermetallic phases and Si particles (primary as well as eutectic) in Al-Si alloys. ${ }^{[13,14]}$

Traditionally, solute hydrogen is considered the main contributor to microporosity formation in aluminum alloys. ${ }^{[15]}$ The solubility of hydrogen in aluminum is considerably lower in the solid than in the liquid state. ${ }^{[16]}$ For this reason, it is generally thought that during solidification, hydrogen is rejected from solution and forms hydrogen pores in the form of molecular $\mathrm{H}_{2}$ gas. However, as it was described by Campbel1 ${ }^{[3]}$ and later confirmed by Tyriakioğlu, ${ }^{[17-19]}$ hydrogen pores cannot form by homogeneous or heterogeneous nucleation during the solidification of aluminum alloys. During pore formation, nucleation is bypassed, and pores grow simply by the inflation of bifilm defects. This growth process is induced by the hydrogen diffusion into the inner gas atmosphere of bifilm defects and the pressure drop in the mushy zone caused by the solidification shrinkage of the metal. ${ }^{[20,21]}$ For this reason, solute hydrogen content should be only controlled when bifilms are present in the liquid alloy, which is, unfortunately, a common circumstance in industrial practice. $^{[22]}$

To reduce the risk of porosity formation in cast parts, a tremendous amount of effort was made in the past to develop degassing melt treatment technologies. The main purpose of these treatments is to lower the solute hydrogen content of liquid alloys. ${ }^{[23,24]}$ In the foundry industry, rotary degassing is one of the most frequently used melt treatment techniques. This method involves the injection of a purging gas into the liquid alloy through a rotating impeller. Nowadays, the purging gas is usually nitrogen or argon; however, in the past, active gases such as chlorine, freon, fluorine, or mixtures of these with nitrogen or argon were also used. ${ }^{[25]}$ Rotary degassing provides smaller and more evenly distributed purging gas bubbles which is advantageous in terms of solute hydrogen-, and also inclusion removal. ${ }^{[26]}$ The treatment is often combined with the application of fluxes which can remarkably increase the inclusion removal efficiency of the treatment. ${ }^{[27]}$ On the other hand, the process window in which the treatment produces better melt quality is small and especially sensitive to small changes in process parameters. ${ }^{[28]}$ If fluxes are not used, the working parameters of rotary degassing units are usually optimized for efficient solute hydrogen removal. These parameters involve (and are not limited to) the rotor geometry, dimensions of the holding vessel and the rotor, metal quantity, purging gas flow rate, the rotational speed of the impeller, treatment time, application of baffle plates, initial and intended hydrogen level, melt temperature, the chemical composition of the melt, and other environmental factors (such as the humidity of the atmosphere and the applied gas lines). ${ }^{[23,24,29]}$

The effect of rotary degassing treatments on the bifilm content of liquid aluminum alloys is not straightforward, and the information available in the literature is often contradictory. Uludağ et al., ${ }^{[30]}$ as well as Uludağ and Dispinar ${ }^{[31]}$ reported that, based on lower Bifilm-Index values, degassing with Ar (for 15 and 20 minutes) effectively reduced bifilm quantity in A356 alloy melts. Contrary, several researchers reported higher bifilm quantity after rotary degassing treatments, which is commonly attributed to the surface turbulence and vortex formation around the impeller shaft, as well as the free melt surface sloshing near the vessel sidewalls, which phenomena can be avoided by using optimal treatment parameters. ${ }^{[32-35]}$ According to Campbell, ${ }^{[3]}$ degassing treatments are only effective in removing relatively large-sized bifilms, while numerous small-sized bifilms can be introduced into the liquid metal during the treatments. This statement is in accordance with the findings of Lazaro-Nebreda et al., ${ }^{[36]}$ Yorulmaz et al., ${ }^{[37]}$ Dispinar and Campbell, ${ }^{[38]}$ as well as Gyarmati et al. ${ }^{[39]}$ As was highlighted by Cao and Campbell, ${ }^{[40]}$ the purging gases, which are often considered inert, could contain trace oxygen and water vapor which can lead to the oxidation of the inner surface of the purging gas bubbles. $\mathrm{N}_{2}$ readily reacts with liquid $\mathrm{Al}$ at temperatures above $700{ }^{\circ} \mathrm{C}$ and forms $\mathrm{AlN}$, which reaction can even be utilized for manufacturing $\mathrm{Al}-\mathrm{AlN}$ composites. ${ }^{[41]}$ Gyarmati et al. ${ }^{[39]}$ suggested that by the consumption of $\mathrm{N}_{2}$, which is caused by the nitridation at the gas bubble/

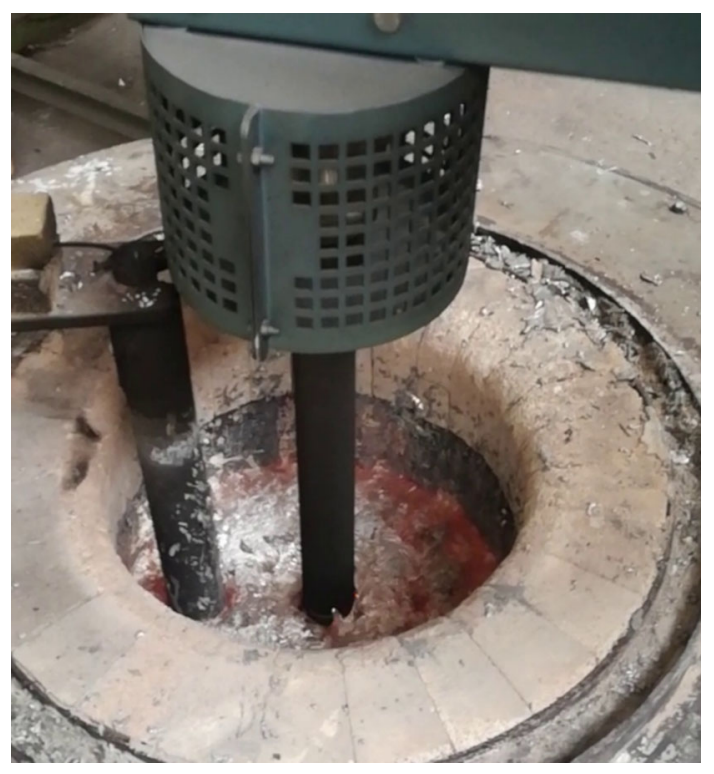

Fig. 1-Experimental setup for rotary degassing. 
melt interface, purging gas bubbles can lose buoyancy which can prevent their rise to the melt surface. In this way, rotary degassing with $\mathrm{N}_{2}$ can cause the formation of numerous small-sized nitride bifilms. If this hypothesis is correct, rotary degassing treatments executed with $\mathrm{N}_{2}$ and Ar should have significantly different effects on the bifilm content of aluminum alloy melts. However, to the best knowledge of the authors, comparative studies in which the bifilm content is quantitatively analyzed cannot be found in the literature. To fill this gap of knowledge, the presented research work aimed to study the effects of multiple rotary degassing treatments executed with $\mathrm{N}_{2}$ and $\mathrm{Ar}$ on the melt quality of aluminum alloys.

\section{MATERIALS AND METHODS}

Two sets of experiments were executed; in both cases, $50 \mathrm{~kg}$ of secondary $\mathrm{Al}-7$ pet $\mathrm{Si}-0.5$ pet $\mathrm{Cu}-0.4$ pet $\mathrm{Mg}$ alloy (EN-AC-45500 or A356 with additional Cu-content), in the form of blocks and returns in 1:1 ratio, was melted in an electric resistance furnace equipped with a clay-graphite crucible at $715{ }^{\circ} \mathrm{C}$. During both experiments, 5-5 consecutive rotary degassing treatments were executed with the same settings but with different purging gases: $\mathrm{N}_{2}$ was used in the first set of experiments and $\mathrm{Ar}$ in the second. In both cases, the purity of the applied gas was above 99.99 pct. For degassing, a Foseco FDU 2-2301 type mobile degasser equipped with a Foseco XSR graphite rotor was utilized (Figure 1). Due to the rather small melt surface, the baffle plate of the degassing unit was not used. Each melt treatment was 10 minutes long; the purging gas flow rate was $7 \mathrm{~L} /$ min, and the impeller rotational speed was $300 \mathrm{rpm}$.

The chemical composition of the alloy was inspected directly after melting, as well as after each melt treatment with optical emission spectroscopy. The chemical composition of the alloy did not vary significantly during the treatments; the average chemical composition values for both set of experiments are given in Table I.

The evolution of the bifilm quantity during the treatments was assessed with the computed tomographic investigation of reduced pressure test (RPT) specimens, which were taken by the immersion of a steel cup (with adequate refractory coating) into the melt. This sampling method provides less entrainment damage compared to the traditional pouring sampling. ${ }^{[42]}$ After melting and following each melt treatment, 2 RPT samples were cast. The preheating of the sampling cups was achieved by contacting the steel cup with the melt surface for 10 seconds. The pressure inside the RPT vacuum chamber was 80 mbar, the specimens stayed in the chamber for 6 minutes. For the evaluation of the

Table I. Chemical Composition Values (in Wt Pct )

\begin{tabular}{lccccccc}
\hline Experiment & $\mathrm{Si}$ & $\mathrm{Fe}$ & $\mathrm{Cu}$ & $\mathrm{Mn}$ & $\mathrm{Mg}$ & $\mathrm{Ti}$ & $\mathrm{Sr}$ \\
\hline $1 . \mathrm{N}_{2}$ & 6.79 & 0.12 & 0.39 & 0.05 & 0.35 & 0.14 & 0.010 \\
$2 . \mathrm{Ar}$ & 6.88 & 0.11 & 0.38 & 0.05 & 0.37 & 0.13 & 0.012 \\
\hline
\end{tabular}

Density-Index (DI), an additional sample was cast in each sampling step, which solidified at atmospheric pressure. The density of the specimens was evaluated by Archimedes principle, and the Density-Index was calculated as:

$$
\mathrm{DI}=\frac{\rho_{\mathrm{atm}}-\rho_{80 \mathrm{mbar}}}{\rho_{\mathrm{atm}}} \times 100
$$

where DI is the Density-Index [pct], $\rho_{\text {atm }}$ and $\rho_{80 \mathrm{mbar}}$ are the densities of the samples $\left[\mathrm{g} \mathrm{cm}^{-3}\right]$ solidified at atmospheric and 80 mbar pressure, respectively. Density-Index is widely used in foundries for the assessment of porosity formation susceptibility. On the other hand, it was reported that RPT could be an effective tool for the characterization of bifilm quantity. ${ }^{[43-45]}$ Bifilms inside RPT samples are inflated during solidification under reduced pressure. This inflation is caused by the hydrogen diffusion into the inner atmosphere of bifilms and the expansion of the entrained gases. ${ }^{[43]}$ In this way, bifilms can be detected more easily in RPT samples with the aid of image analysis or radiographic analysis. ${ }^{[20]}$ In this study, computed tomography was implemented for the characterization of the double oxide film content of the liquid alloy. GE Seifert X-Cube Compact $225 \mathrm{kV}$ apparatus was used for radiographic image acquisition with $0.8 \mathrm{~mA}$ tube current and $135 \mathrm{kV}$ acceleration voltage. During the rotation of each sample, 900 images were acquired. The image reconstruction and the segmentation, as well as the analysis of pores present in the RPT specimens, were conducted with VGSTUDIO MAX 3.4 software. During the porosity analysis, objects with a volume smaller than $0.1 \mathrm{~mm}^{3}$ and pores with a probability value lower than 0.5 were ignored. A more detailed description of the CT analysis is given in Reference ${ }^{[20]}$. Three parameters were evaluated by the CT-aided porosity analysis: the volumetric pore number density $\left[\mathrm{cm}^{-3}\right]$, which is proportional to the number of bifilms present in a given volume of liquid metal ${ }^{[20,46]}$; the volume fraction of pores [pct], which is mainly dependent on the solute hydrogen and entrained air quantity, as well as the structural properties of bifilms ${ }^{[7,42]}$; the specific pore surface area $\left[\mathrm{mm}^{-1}\right]$ which can be defined as the surface area of pores present in 1 $\mathrm{mm}^{3}$ of the RPT specimens. The latter metric has been named as Bifilm Spatial Index (BSI) by Song et al., ${ }^{[47]}$ which (according to the authors) can be treated as an improved version of the Bifilm-Index first introduced by Dispinar and Campbell. ${ }^{[4]}$

The changes in melt quality during the experiments were also characterized by K-mold samples. The $\mathrm{K}$-mold specimens can be used for the evaluation of the inclusion content of liquid metals by the investigation of the fracture surfaces of the samples. The so-called K-value can be given by the following formula:

$$
K=\frac{S}{n}
$$

where $S$ is the total number of inclusions found, $n$ is the number of the investigated fracture surfaces, $K$ is the K-mold value, which is a dimensionless number. ${ }^{[48]}$ After melting and following each melt treatment, 5 

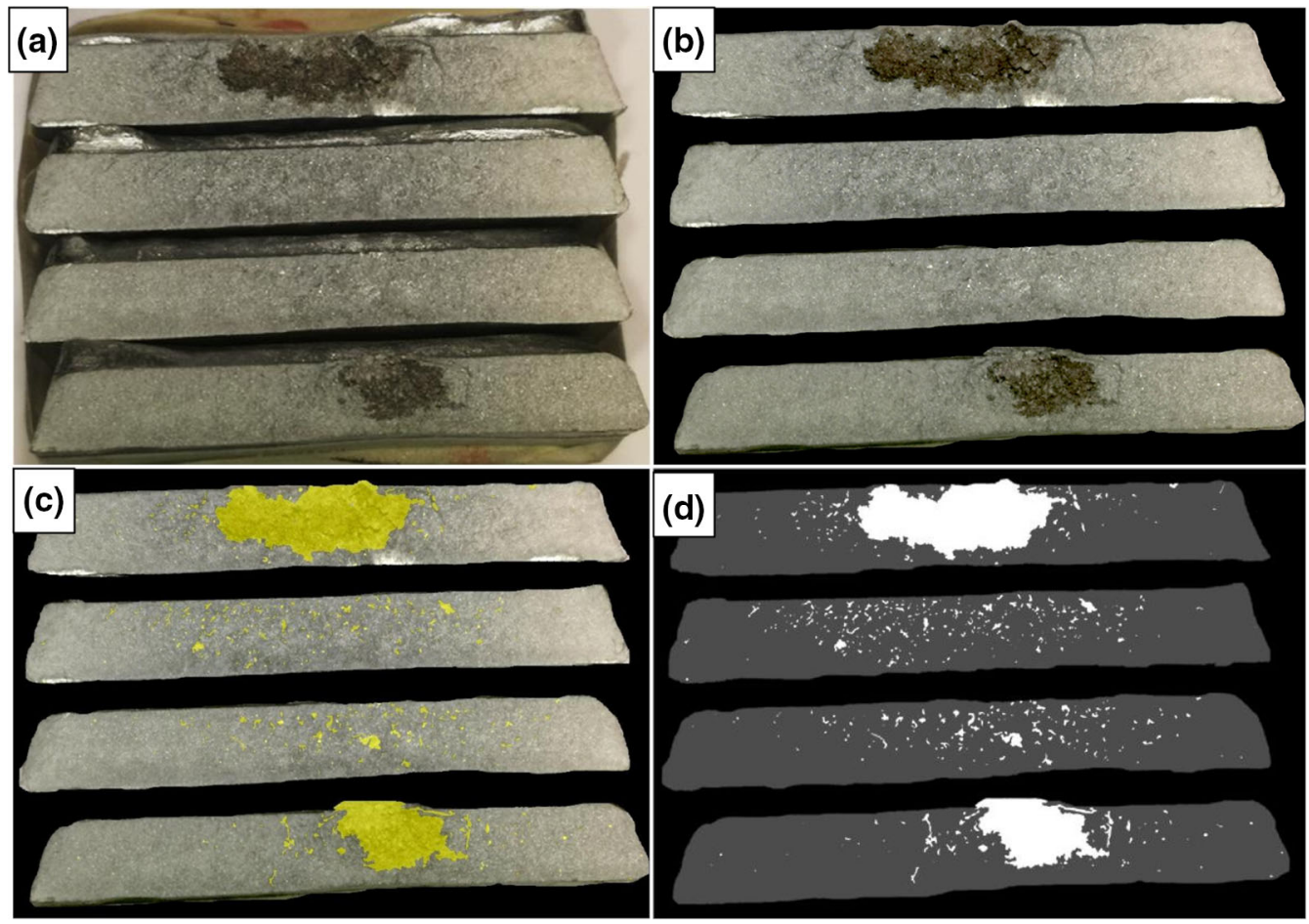

Fig. 2-Steps of image analysis of the fracture surfaces of K-mold specimens: $(a)$ initial image, $(b)$ segmented fracture surfaces, $(c)$ segmentation of defects and $(d)$ binary image.

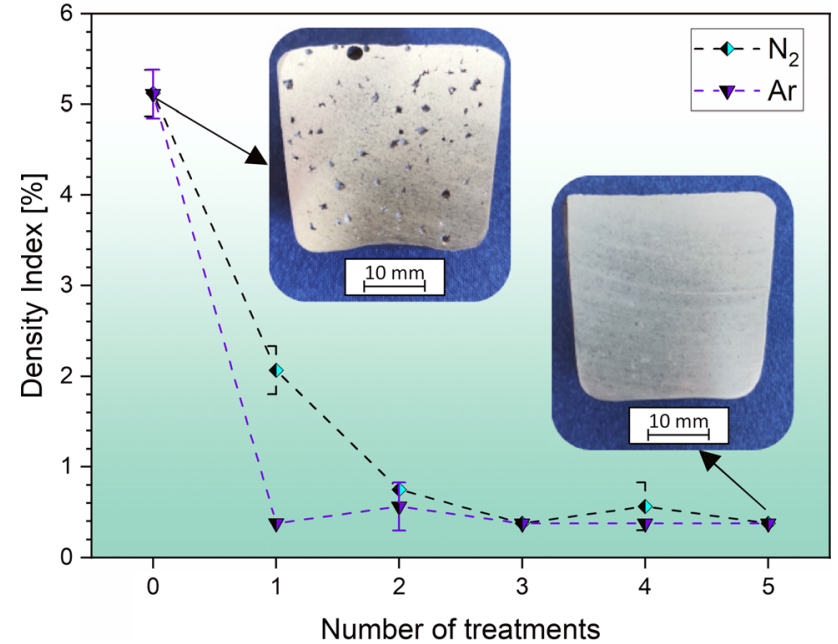

Fig. 3-Density-Index results.

K-mold specimens were cast into the preheated $(200$ $\left.{ }^{\circ} \mathrm{C}\right) \mathrm{K}$-mold. The fracture surfaces of the pieces were investigated with a Zeiss Stemi 2000-C stereomicroscope at a magnification of $\times 25$. Macro photographs were taken from each sample with a high-resolution (64 megapixel) camera. The photographs were subjected to image analysis with the aid of the Image Processing Toolbox application of Matlab. The segmentation of inclusions was achieved in two consecutive steps (Figure 2): first, the fracture surfaces were separated from the background by manual segmentation and the active contours function of the software
(Figure 2(b)), then the inclusions were segmented by the graph cut and active contours functions (Figure 2(c)). The segmentation was based on the differences in the color of the defects and the matrix. Based on the detected defects, areal number density $\left[\mathrm{mm}^{-2}\right]$ and defect area fraction [pct] was calculated for each $\mathrm{K}$-mold sample. For a better understanding of the nature of defects present on the fracture surfaces, scanning electron microscopic (SEM) investigations were implemented with a Zeiss EVO MA 10 scanning electron microscope, which is equipped with an energy-dispersive X-ray spectroscopy (EDS) system.

\section{RESULTS AND DISCUSSION}

The DI values evaluated after melting and following the melt treatments for both sets of experiments, as well as representative photographs of the RPT samples cast before the first and after the fifth treatment, are presented in Figure 3. Based on the results, the initial DI was relatively high and was nearly the same during both experiments. After the first treatments, the DI was reduced to an average value of 2.07 and 0.38 pct in the case of treatments executed with $\mathrm{N}_{2}$ and Ar, respectively. Following the second treatment, the DI value was further decreased in the case of the treatment with $\mathrm{N}_{2}$, but no further improvement was achieved by $\mathrm{Ar}$ purging. During the last three treatments, the DI was similarly low in both cases. The results indicate that the lower limit of DI was reached more rapidly by utilizing Ar purging gas. 

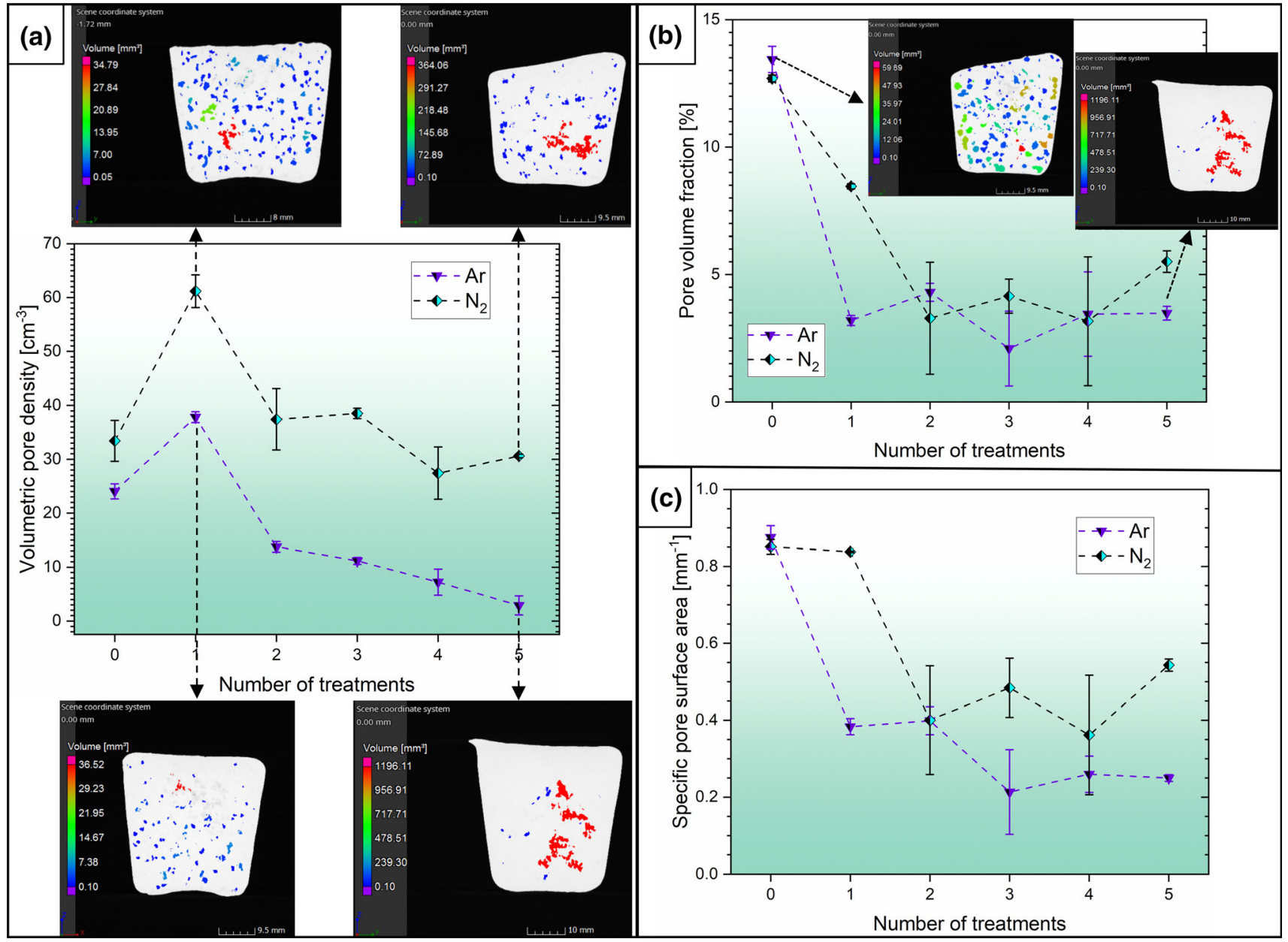

Fig. 4-Variation of $(a)$ pore number density, $(b)$ pore volume fraction, and $(c)$ specific pore surface area values during the experiments.

The average volumetric pore number density, pore volume fraction, and specific pore surface area values are given in Figure 4. By the comparison of the changes in porosity characteristics induced by the treatments, remarkable differences can be noticed between the evolution of the pore number density and specific pore surface area, which indicate notable differences between the melt qualities even for cases when the DI is nearly the same (such as after the third and fifth treatments). After the first treatments, the average volumetric pore density increased significantly regardless of the purging gas selection (Figure 4(a)), while the pore volume fraction decreased similarly to the DI values (Figure 4(b)). Specific pore surface area changes according to a similar tendency as pore volume fraction (Figure 4(c)), which indicates that this parameter is strongly influenced by the volume of pores present in the samples.

Figure 5 shows the variation of the volume of the largest pores found in the RPT specimens. Regardless of the purging gas selection, the first treatments resulted in a slightly smaller maximum pore volume, which could be the result of lowered solute hydrogen content. On the other hand, after the second treatment with Ar, the maximum pore volume increased significantly.
Following the fourth treatment with Ar, the volume of the largest pore radically increased; large, central pores could be found in the samples (Figure 5(b)). However, in the case of degassing with $\mathrm{N}_{2}$, the maximum pore volume values were stagnated and were substantially smaller (see Figure 5(c)) than the ones detected after multiple degassing with Ar.

The differences between maximum pore sizes can be traced back to the differences in the bifilm population in the samples. After the second treatment, the Density-Index values were similarly low in each case (Figure 3 ) which indicates low solute hydrogen content, which is to be expected after two consecutive degassing treatments. In this way, the main contributor to pore growth during the solidification of the RPT samples was the pressure drop in the mushy zone caused by the shrinkage of the alloy. As the solidification conditions were the same in both experiments, similar shrinkage behavior should be expected in each sample, regardless of the purging gas selection. On the other hand, in the case of degassing with $\mathrm{N}_{2}$, the pore number density results (Figure 4(a)) indicate a larger population of bifilms. In this way, during solidification, the pressure drop, which is caused by the shrinkage, affected multiple different pore initiation sites (i.e., bifilms) in the samples. As a result, 


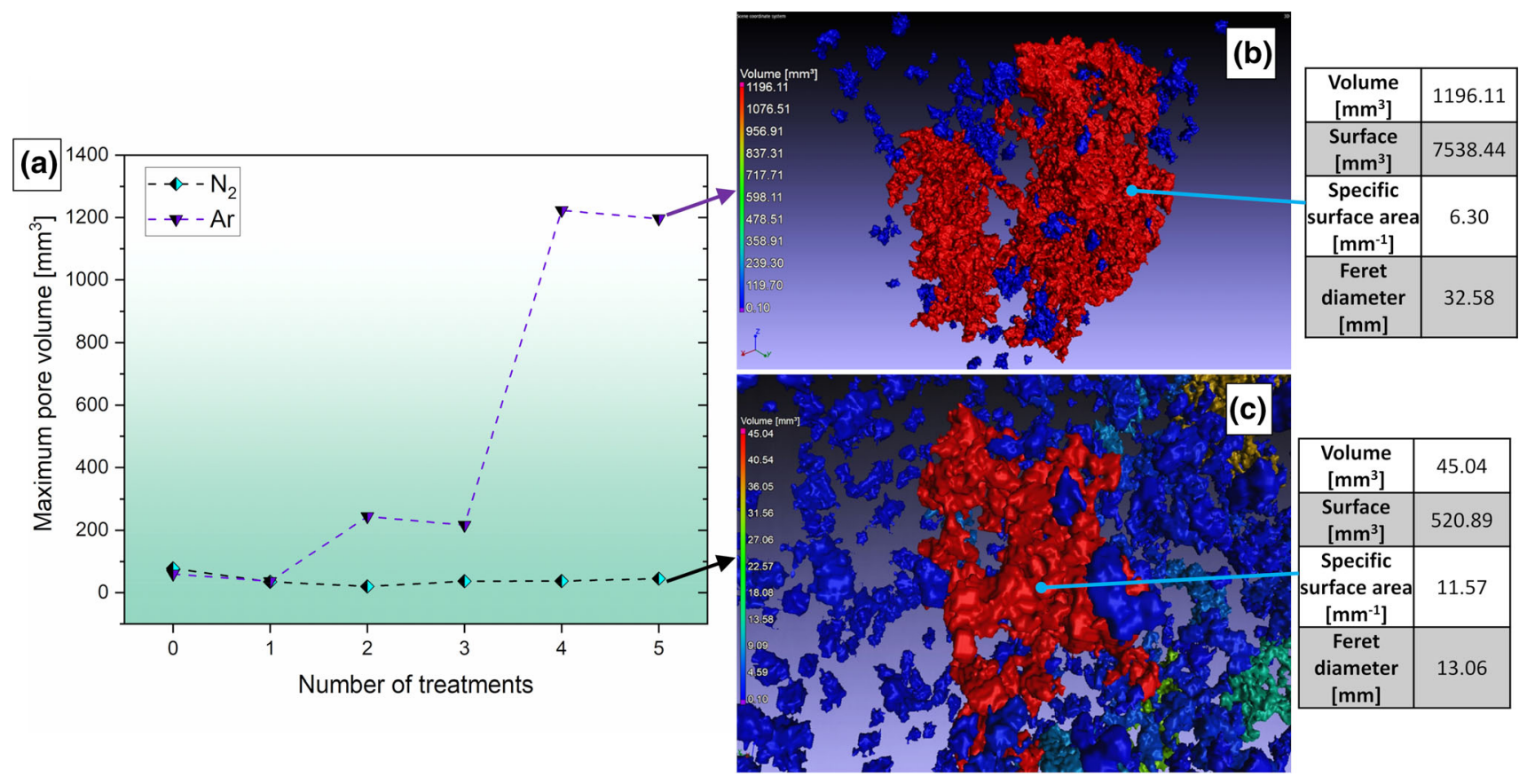

Fig. 5-Evolution of the $(a)$ volume of the largest pores found in the RPT pieces, $(b)$ reconstructed CT image of the largest pore found in the RPT specimen cast after the fifth treatment with $\mathrm{Ar}$, and $(c)$ with $\mathrm{N}_{2}$.

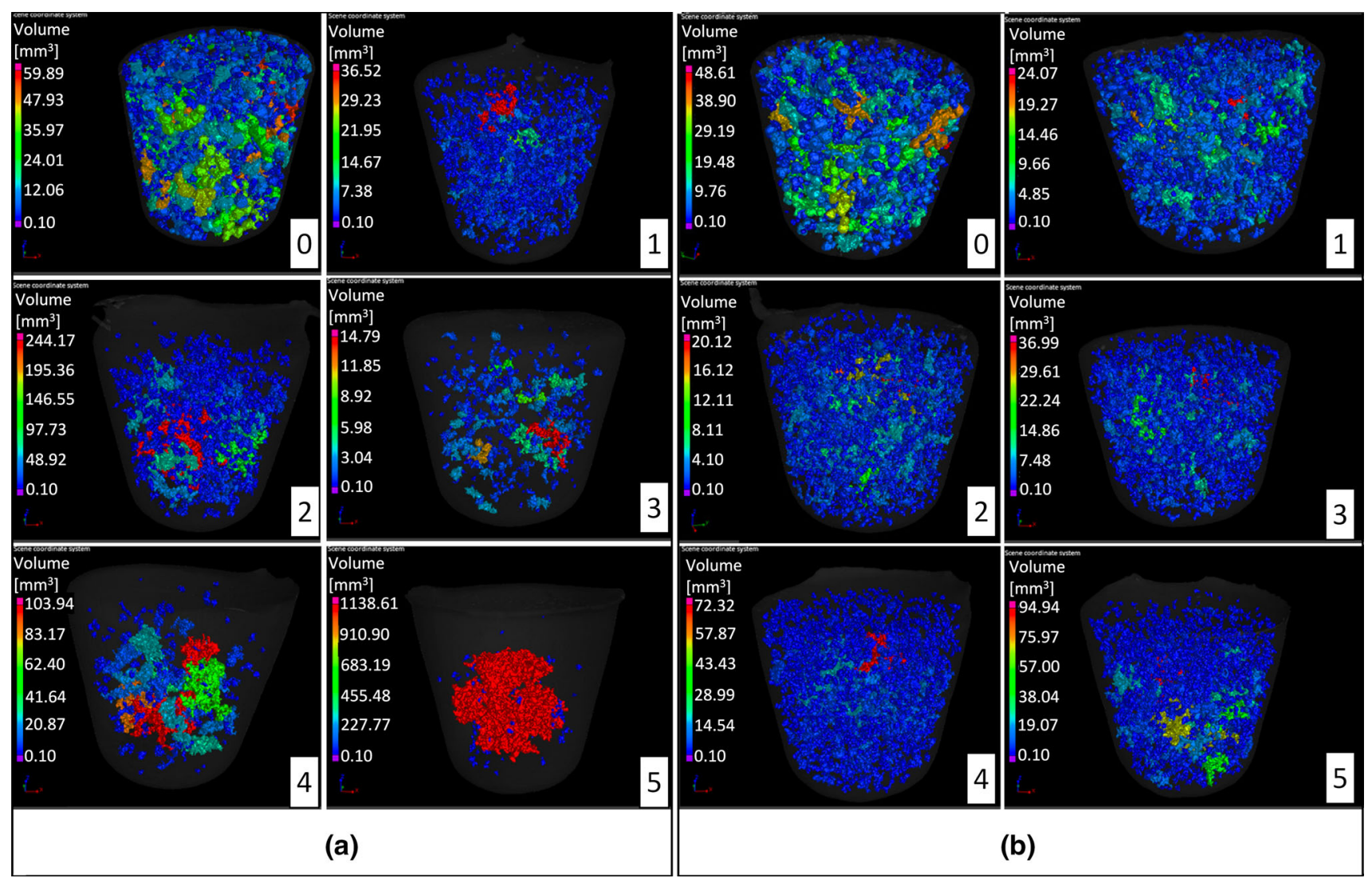

Figure 6-Evolution of porosity in RPT samples by increasing the number of melt treatments using $(a) \operatorname{Ar}$ and $(b) \mathrm{N}_{2}$. 
instead of the large central shrinkage pore, which can be initiated by only one bifilm, multiple smaller pores were formed in the alloy treated with $\mathrm{N}_{2}$.

Figure 6 presents representative three-dimensional images of the pores found in the RPT samples during the CT-aided porosity analysis. The number of executed degassing treatments is indicated with numbers (from 0 to 5) in each CT image. By the comparison of the changes in porosity characteristics induced by the treatments (Figures 6(a) and (b)), remarkable differences can be noticed between the evolution of the size and quantity of pores, which indicate notable differences between the melt qualities even for cases when the DI is nearly the same (such as after the third and fifth treatments).

The increased pore number density (which normally indicates higher bifilm content) in the samples cast from melts treated with $\mathrm{N}_{2}$ can be the result of multiple phenomena. It is possible that because of the decreased solute hydrogen content, bifilms could not inflate as much as before the treatments; in this way, semi-inflated bifilms could appear as separate pores in the CT images (for example, a convoluted bifilm with two relatively large air pockets can appear as two separate pores ${ }^{[49]}$ ). It is also possible that some of the larger bifilms were removed from the liquid alloy, while some were sheared into smaller bifilms by the rotating impeller. ${ }^{[36]}$ The entrainment of the surface oxide film of the melt by the rotating impeller, as well as the formation of bifilms by purging gas bubbles contaminated with $\mathrm{O}_{2}$ or $\mathrm{H}_{2} \mathrm{O}$ vapor, are also probable. ${ }^{[40]}$ On the other hand, the increased number of treatments with $\mathrm{Ar}$ and $\mathrm{N}_{2}$ resulted in visible differences between the pore size and spatial distribution, as well as the pore number density, which cannot be explained by these aspects. After the first degassing using Ar, the consecutive treatments resulted in continuously decreasing pore number density (Figure 4(a)), which can be clearly seen in Figure 6(a): by increasing the number of treatments, the number of visible pores is greatly reduced in the CT images. This is

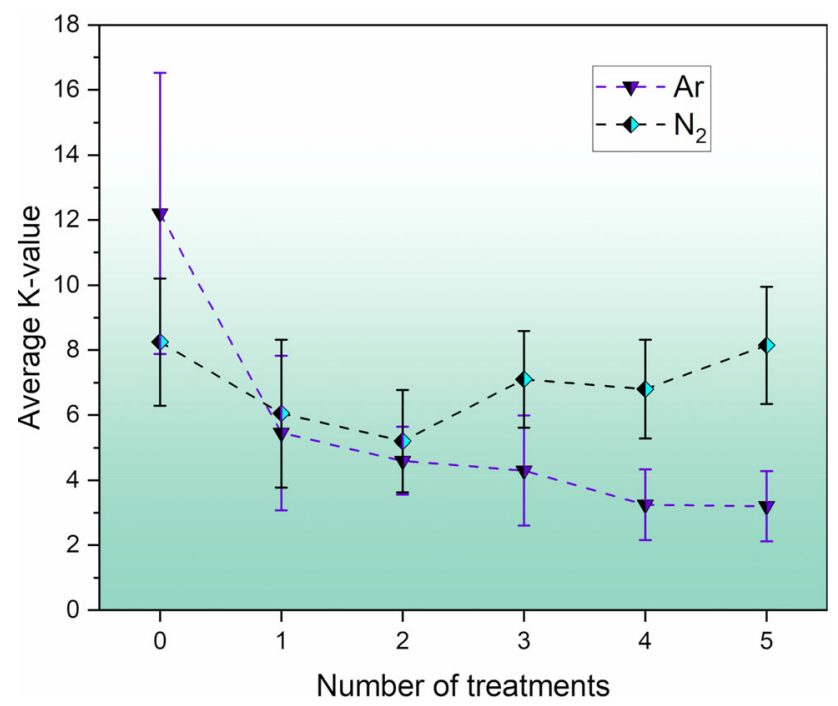

Fig. 7-Evolution of average K-values during the experiments. a clear sign of continuously improving melt quality; that is, the number of removed bifilms was greater than that of the bifilms formed during the treatments. After the last treatment with Ar, a large central pore, presumably created by shrinkage and a few small-sized pores, could be detected inside the RPT samples. The authors have reported similar pore distribution for RPT samples cast after rotary degassing treatments combined with flux addition. ${ }^{[20]}$ On the other hand, the effect of treatments executed with $\mathrm{N}_{2}$ is not straightforward: numerous small-sized pores can be observed even after the last treatment (Figure 6(b)), which indicates the presence of a great number of bifilms. Besides the fact that the number of detected pores was remarkably higher for all sampling steps, in some cases, the consecutive treatments with $\mathrm{N}_{2}$ resulted in increased pore number densities (such as after the third and fifth treatments). This clearly indicates that the number of bifilms that were created during these treatments is significantly more than that of the removed ones.

The higher inclusion content of the melts treated with $\mathrm{N}_{2}$ was detectable during the analysis of the fracture surfaces of K-mold samples too. Figure 7 shows the results of $\mathrm{K}$-value evaluation with the aid of a stereomicroscope, while Figure 8 presents the results of image analysis of the fracture surfaces. By increasing the number of treatments with Ar, the K-values are notably reduced, while $\mathrm{N}_{2}$ purging resulted in lowered $\mathrm{K}$-values only after the first two treatments.

Afterward, the K-values increased, which indicates the formation of inclusions during the treatments. The difference between degassing with $\mathrm{Ar}$ and $\mathrm{N}_{2}$ is even more significant in terms of the areal number density of defects (Figure 8(a)). The number density is continuously increasing by the utilization of $\mathrm{N}_{2}$, while the application of Ar resulted in continuously decreasing defect number density. A more random variation can be observed in the case of area fraction results (Figure 8(b)).

Based on the analysis of the K-mold samples and RPT specimens, it can be concluded that after the first treatment, the consecutive degassing treatments with $\mathrm{Ar}$ gas remarkably improved melt quality, i.e., reduced bifilm content. On the other hand, no significant improvement was achieved by degassing with $\mathrm{N}_{2}$. The number of bifilms present in the melt was even increased by the treatments with $\mathrm{N}_{2}$, which is in accordance with the findings of Gyarmati et al. ${ }^{[39]}$ and the LiMCA data reported by Tremblay and Maltais. ${ }^{[50]}$

During the investigation of $\mathrm{K}$-mold samples, in all cases, film-like discontinuities were found, which comprised of two distinct layers that could be clearly seen on the opposing fracture surfaces (Figure 9). Based on this, the investigated inclusions were bifilms. In some cases (such as Figures 9(b) and (c)), the two halves of the bifilms had a different shade of color, which is most probably due to differences in the local oxidation/ nitridation time, as well as the local chemical composition of the layers.

By the SEM investigation of pores found on the fracture surfaces, it was found that the pores were formed due to the presence of bifilm defects. Figure 10 presents the backscattered electron (BSE) SEM images 
(a)

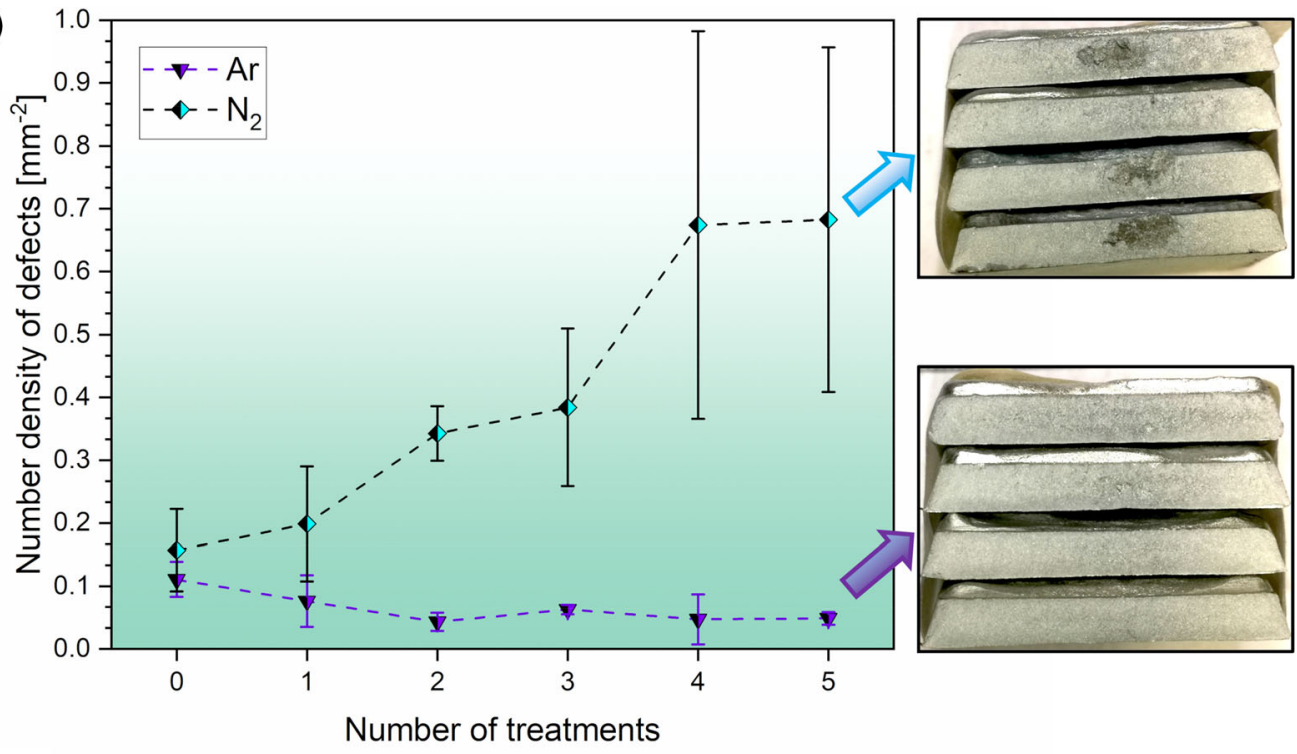

(b)

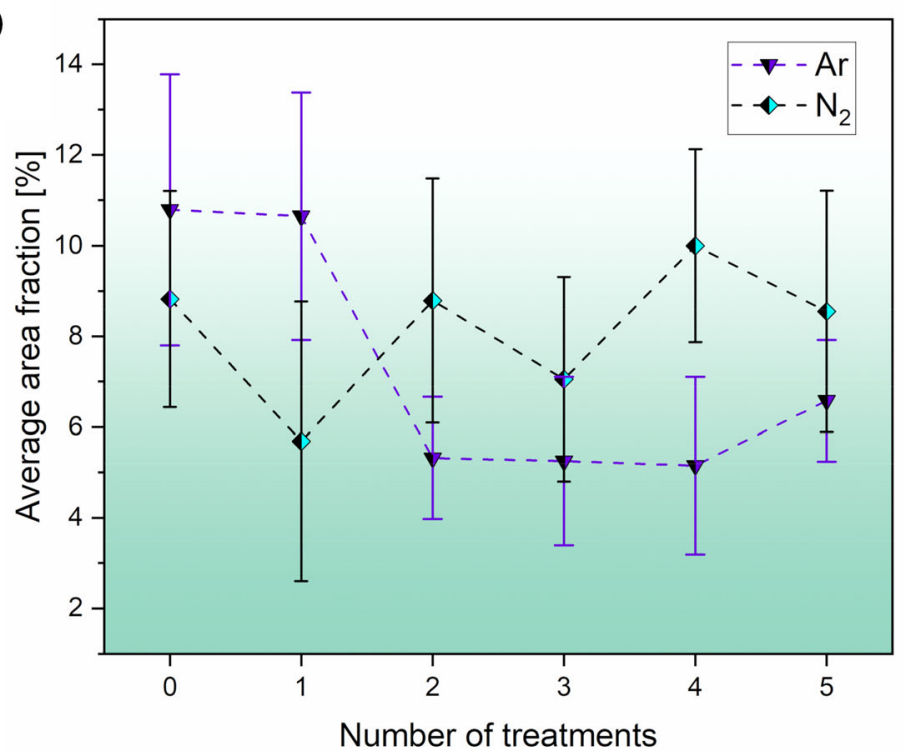

Fig. 8- (a) The number density and $(b)$ area fraction of defects detected by image analysis on the fracture surfaces of K-mold samples.

of O-rich inhomogeneities found inside the pores of a K-mold sample cast directly after melting. In Figure 10(a), based on the high oxygen content measured in areas 1 and 2 , a relatively thick oxide film is covering the $\alpha-\mathrm{Al}$ dendrites and the interdendritic regions of the microstructure. The high oxygen concentrations and the visible cracks on the oxide film indicate an advanced oxidation state.

Newly formed oxide films on the surface of liquid aluminum alloys, with growth times less than 10 seconds, are flexible, and they bend when they are distorted or stretched. This results in fine creases and folds, which are common morphological characteristics of these thin, so-called young oxide films. With increased oxidation time, however, as oxide films gradually thicken, they become more and more brittle. These so-called old oxide films, due to their brittleness, are easily cracking due to the stresses induced by liquid flow during melt treatments and casting or by the stresses occurring during solidification. ${ }^{[3,51]}$ The oxide inclusion presented in Figure10(a) probably can be originated from the oxide skin of the charge material. In Figure 10(b), the dendrites are partly covered by a thick granular (old) oxide layer (area 4). On the other hand, in area 3, only a thin young oxide film could be present, which is practically invisible due to its thinness and its ability to wrap around the dendrites perfectly due to the pressure drop in the interdendritic regions during the solidification of the alloy.

Figure 11 presents the images of oxide films present in pores found in K-mold specimens cast after the first treatment with Ar. In Figure 11(a), a thick old oxide film can be seen, which seems to be decorated with oxide crystals. This indicates that by increased oxidation time, 


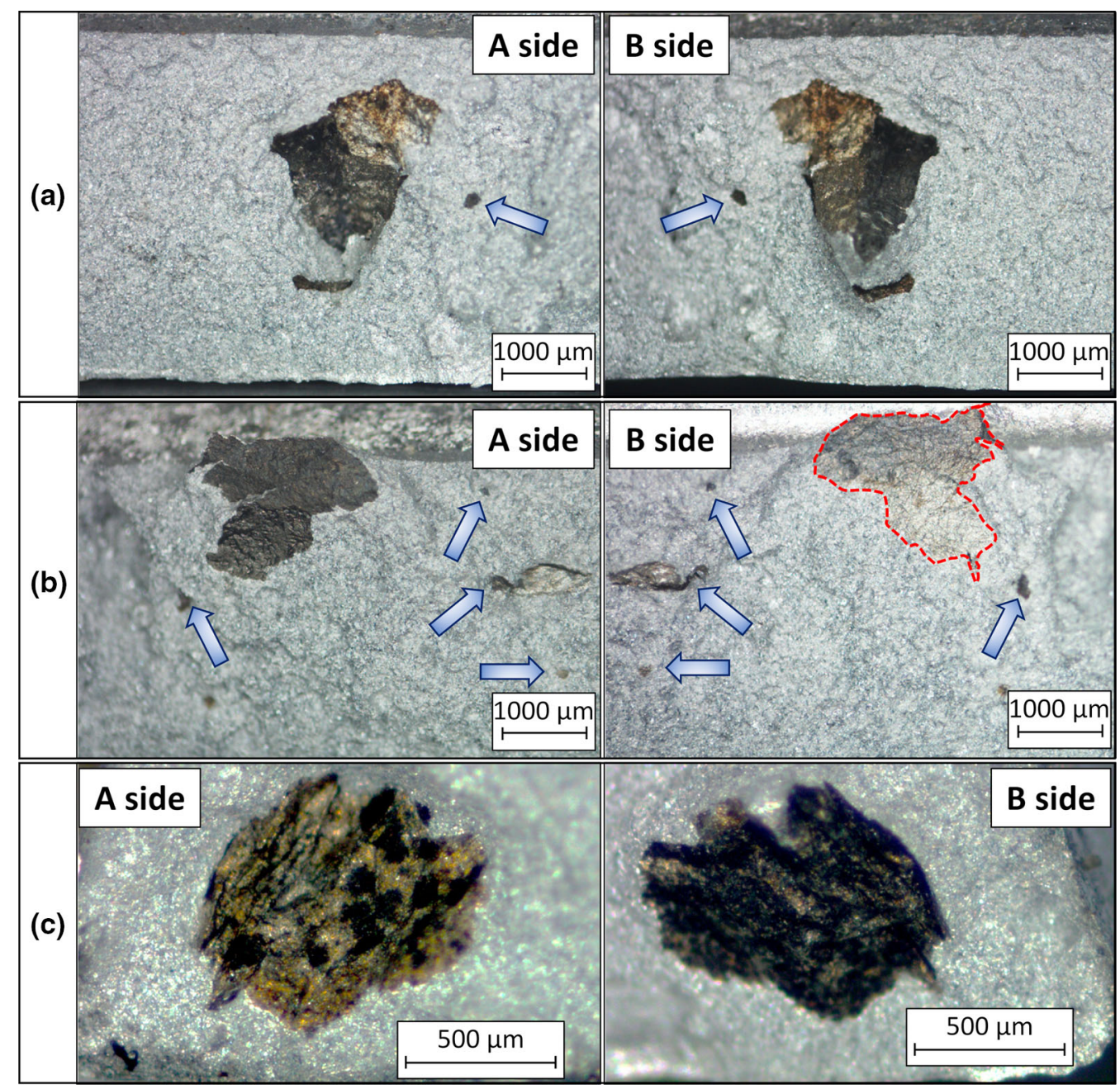

Fig. 9- $(a-c)$ Examples of bifilm defects found on the fracture surfaces of K-mold specimens.

the structure of the oxide films is gradually transformed. It is reported in the literature that during the extended oxidation of liquid aluminum alloys, crystalline oxide particles can be formed on the surface of the originally formed oxide film, which is a highly possible reason for the appearance of the oxide layer presented in Figure 11(a). ${ }^{[52,53]}$

In contrast, Figure 11(b) presents a vanishingly thin young oxide film that can only be detected by its small-sized wrinkles (indicated by yellow arrows) that formed between the dendrite arms. Based on the thickness of the wrinkles, the thickness of the presented oxide film is less than about $0.5 \mu \mathrm{m}$ [54].

In the case of samples cast from melts treated with $\mathrm{N}_{2}$, most of the investigated inclusions contained a significant amount of nitrogen. In Figure 12, two examples are shown for nitrogen-rich film-like inclusions. Figures 12(a) and (b) show low magnification BSE SEM images of the films, while Figures 12(c) and (d) show higher magnification images of the surface of the defects. The results of the EDS analyses conducted in areas 1 and 2 are presented in Figure 12(e). In area 1 of Figure 12(a), the measured nitrogen concentration is significantly higher than the oxygen concentration, which indicates that the inclusion is mainly the product of nitridation. Similarly, in area 2 of Figure 12(b), the nitrogen content is slightly higher than the oxygen content. Similar inclusions were not found in samples cast from the melt treated with Ar. The presence of inclusions high in nitrogen is in accordance with the results reported by Gyarmati et al., ${ }^{[39]}$ who found similar defects after rotary degassing with $\mathrm{N}_{2}$.

The reason for the presence of $\mathrm{Cu}, \mathrm{Fe}$, and relatively high $\mathrm{Mg}$ peaks shown in Figure 12(e) is most probably that there is interdendritic microstructure within the interaction volume of the incident electron beam underneath the investigated film-like inclusions. The alloy composition $(\mathrm{Cu}, \mathrm{Mg}$, and $\mathrm{Fe}$ content $)$ is in a range where the formation of $\mathrm{Al}_{2} \mathrm{Cu}, \mathrm{Mg}_{2} \mathrm{Si}$, and various Fe-containing intermetallic phases is favored in the interdendritic microstructure of the alloy. ${ }^{[55,56]}$ In the case of inclusions shown in Figures 10 and 11), the oxide layers are on the surface of $\alpha-\mathrm{Al}$ dendrites. In this way, there are no intermetallic compounds within the interaction volume. Another contributor to the higher $\mathrm{Mg}$ content is that the investigated films contain spinel $\left(\mathrm{MgAl}_{2} \mathrm{O}_{4}\right)$, which is to be expected, as the $\mathrm{Mg}$ concentration in the alloy is in the range where spinel formation is thermodynamically 

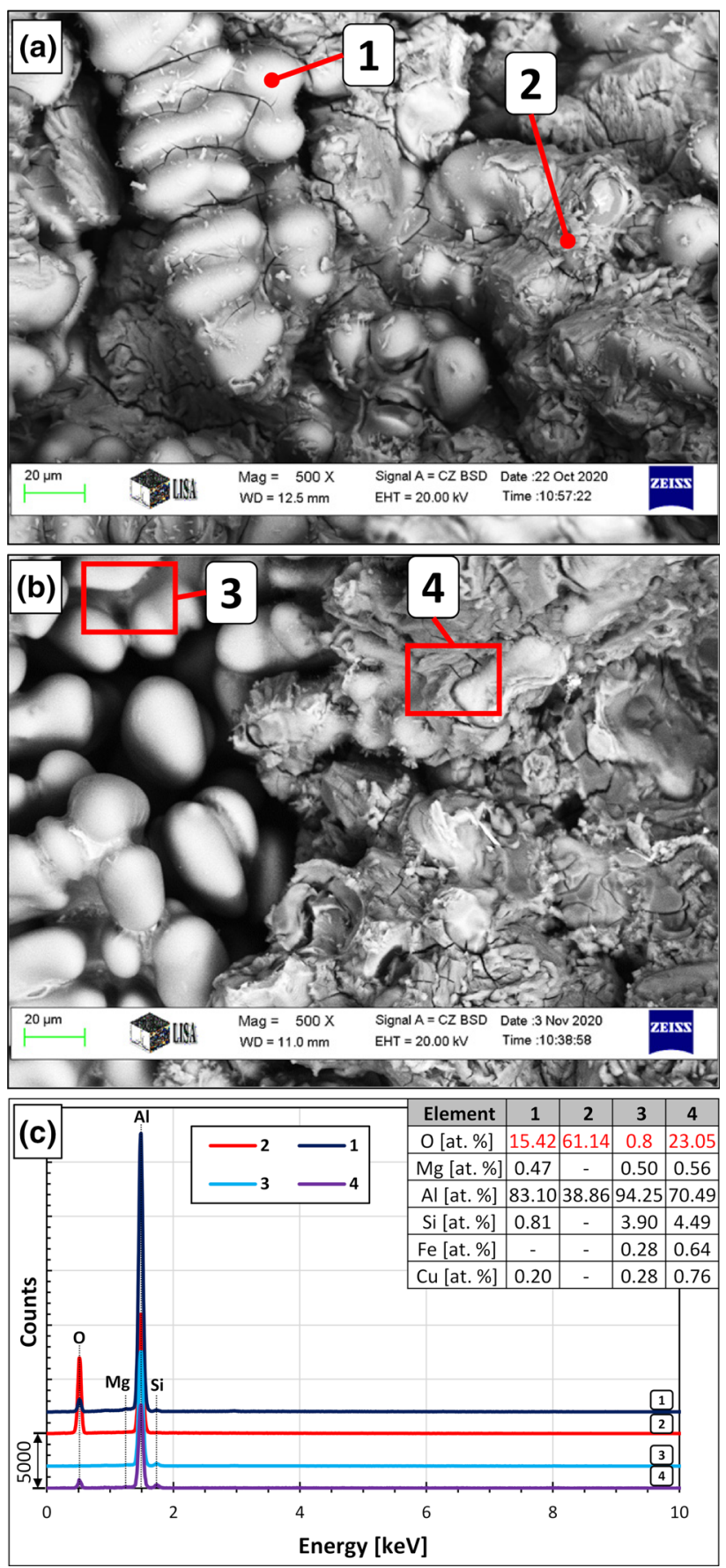

Fig. 10- $(a-b)$ BSE SEM images of the inner surface of pores found in K-mold samples cast directly after melting, $(c)$ the results of the EDS analyses conducted in the indicated areas.

favored. ${ }^{[51,53]}$ The relatively high oxygen content suggests that $\mathrm{O}_{2}$ or $\mathrm{H}_{2} \mathrm{O}$ could be present in the purging gas bubbles as impurities. In our case, the thermodynamically most stable nitride, which can form during the nitridation of the gas bubble/melt interface, is AlN, which is most likely the main component of the inclusions shown in Figure 12. ${ }^{[39,57]}$

The fact that the treatments executed with $\mathrm{N}_{2}$ resulted in increased bifilm content (see Figures 4(a), 7, and 8(a) and $\mathrm{N}$-rich inclusions were found in the samples cast from the melts treated with $\mathrm{N}_{2}$ clearly indicate that the
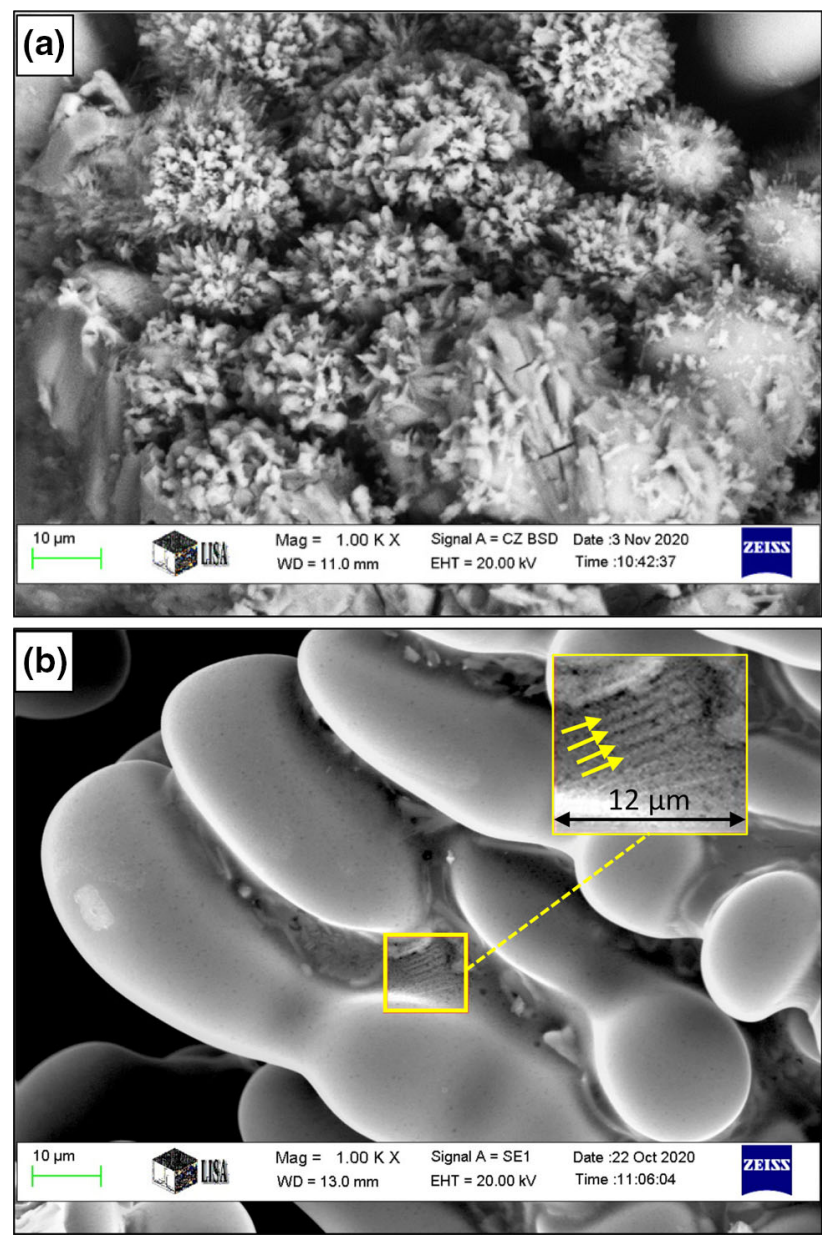

Fig. 11-(a) Old and (b) young oxide films found in pores inside K-mold samples cast from the melt treated with Ar.

chemical interaction between the purging gas and the liquid alloy resulted in the formation of numerous nitride bifilms. Besides that, even high-purity $\mathrm{N}_{2}$ gas can contain a small amount of $\mathrm{O}_{2}$ as an impurity, and graphite rotors and shafts are prone to water vapor absorption from the atmosphere. ${ }^{[3,40]}$ As thermodynamically oxides are more easily formed than nitrides, oxides will form on the purging gas bubble surface until most of the $\mathrm{H}_{2} \mathrm{O}$ vapor and $\mathrm{O}_{2}$ gas is consumed, and the partial pressure of these gases is locally reduced. Thereafter, $\mathrm{N}_{2}$ will start to react with the liquid metal to form AlN, which causes the nitridation of the already oxidized interface. This will lead to the formation of mixed oxide-nitride films, like the ones shown in Figure 12.

The nitridation rate inside $\mathrm{N}_{2}$ containing bubbles could be rather different depending on many factors. Raiszadeh and Griffiths ${ }^{[58]}$ reported that the $\mathrm{O}_{2}$ and $\mathrm{N}_{2}$ gas inside air bubbles (with $13 \mathrm{~mm}$ diameter and $40 \mathrm{~mm}$ height), which were trapped in different liquid aluminum alloys at $700{ }^{\circ} \mathrm{C}$, was consumed by the chemical reaction with the melt to form oxides $(\mathrm{Ca}$ - and $\mathrm{Sr}$-containing oxides, $\mathrm{MgAl}_{2} \mathrm{O}_{4}$ and $\mathrm{MgO}$ depending on the alloy composition) and AlN. Based on this, the ongoing nitridation of the inner surface of an $\mathrm{N}_{2}$ purging gas 


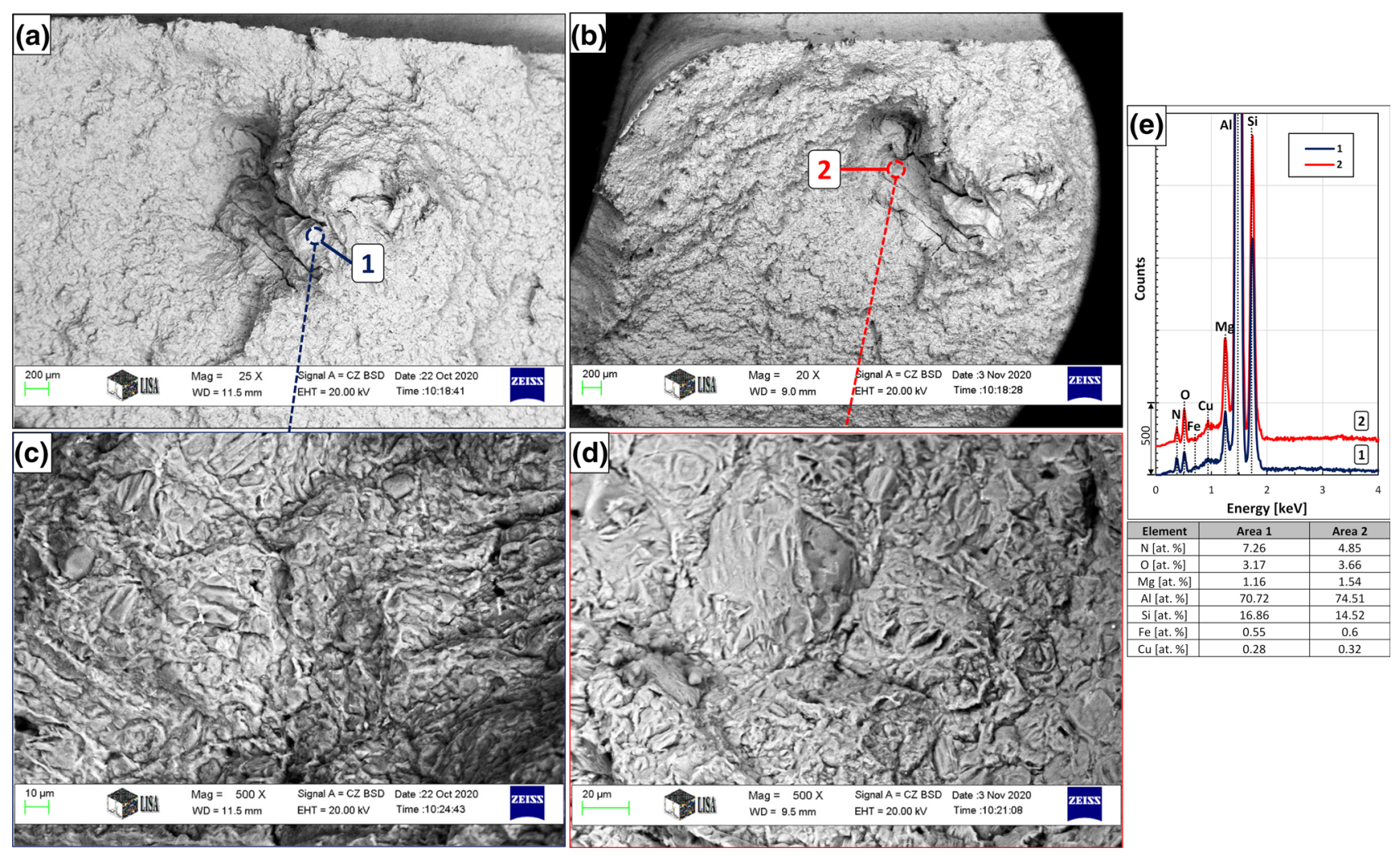

Fig. 12-(a), (b) Nitrogen- and oxygen-bearing film-like inclusions found in K-mold samples cast after the fifth degassing with $\mathrm{N}_{2},(c),(d)$ higher magnification BSE SEM images of the inclusions, and (e) results of the EDS analysis of the indicated areas.

bubble can cause a reduction in the volume of the bubble. However, according to the results of the mentioned authors, ${ }^{[58]}$ the total time needed for the consumption of the inner atmosphere of air bubbles was several hours. This can be attributed to the relatively large size and low specific surface area of the investigated bubbles. Based on the semi-empirical mathematical model of Raiszadeh and Griffiths, ${ }^{[59]}$ the entrained air within a small-sized bifilm defect with a large surface-to-volume ratio can be consumed within 3 minutes. Gyarmati et al. ${ }^{[39]}$ used the same mathematical model and estimated that the time needed for an $\mathrm{N}_{2}$ gas bubble with a $2 \mathrm{~mm}$ diameter to lose its gas content is 13 minutes. Similar consumption rates were reported by El-Sayed et al., ${ }^{[60]}$ who reported that the times required for typical bifilm defects $(2.2 \times 2.2 \times 0.1 \mathrm{~mm})$ to lose their entire oxygen and nitrogen contents at $720{ }^{\circ} \mathrm{C}$ were about 6 minutes, in the case of $\mathrm{Al}-5 \mathrm{Mg} ; 9$ minutes, in the case of a commercial purity $\mathrm{Al}$; and 25 minutes in the case of $\mathrm{Al}-7 \mathrm{Si}-0.3 \mathrm{Mg}$ alloy due to the different oxides formed on the gas/melt interface and the differences in the structure and permeability of these oxides. In contrast, the time needed for the oxygen to be consumed (which shows the onset of nitridation) was estimated to be around 1 minute. For a larger initial bubble volume (6 $\mathrm{mm}$ diameter and $5 \mathrm{~mm}$ height), the experimental results of the same authors showed that during a 40 minute holding period, the bubbles in CP-Al lost about 75 pct $\mathrm{N}_{2}$ content. In $\mathrm{Al}-7 \mathrm{Si}-0.3 \mathrm{Mg}$ alloy, the bubble lost 25 pet of its $\mathrm{N}_{2}$, while in Al-5Mg, 90 pct of the $\mathrm{N}_{2}$ content was consumed. For all three alloys, the onset of nitridation was about 8 minutes.

It must also be highlighted that the concentration and thus the partial pressure of oxygen is much lower in $\mathrm{N}_{2}$ purging gas bubbles than in air bubbles. In this way, if there is an initial oxide film due to the impurities of the gas system, then it is much thinner in $\mathrm{N}_{2}$ bubbles than in air bubbles. For this reason, the onset of nitridation of the bubble surface can be considered to take place instantaneously as the $\mathrm{N}_{2}$ is injected into the liquid alloy. As in the case of purging gas bubbles, there is no relatively thick oxide layer on the interface (as in the case of air bubbles); the process should be faster than in air bubbles. During the treatments with $\mathrm{N}_{2}$, numerous purging gas bubbles can be trapped under the dross layer formed on the melt surface for several minutes. By the consumption of $\mathrm{N}_{2}$ inside the trapped purging gas bubbles, which is caused by the continuous nitridation at the gas bubble/melt interface, it is highly possible that gas bubbles can lose buoyancy which can prevent their rise to the melt surface even after the dross is removed. In this way, rotary degassing with $\mathrm{N}_{2}$ can cause the formation of numerous small-sized nitride bifilms. The nitridation process can even be accelerated as a result of tear formation on the surface of the nitride layers as a 



Fig. 13-Image of the melt surface in the fifth minute of the third degassing treatment with $(a)$ nitrogen and $(b)$ argon.

result of bulk turbulency caused by the rotating impeller. However, the consumption rates of $\mathrm{N}_{2}$ and the behavior of purging gas bubbles need further investigation in the future.

Whether the purging bubbles are trapped in the bulk melt is highly dependent on the surface conditions of the melt and on dross formation. During the first two treatments, regardless of the purging gas selection, a thick dross layer formed on the surface of the melt within the first 3 minutes of the treatments. After the second treatment, this behavior did not change significantly in the case of utilizing $\mathrm{N}_{2}$ (Figure 13(a)). On the other hand, the formation of this thick dross layer could not be seen in the case of degassing with Ar (Figure 13(b)). Increasing the number of treatments with Ar apparently resulted in lowering the amount of dross formed. This difference could be one of the main reasons why degassing with $\mathrm{N}_{2}$ resulted in increased bifilm content. During the treatments, purging gas bubbles could be accumulated under the dross layer formed on the melt surface. In these bubbles, the continuous nitridation of the bubble/melt interface could lead to the formation of nitride bifilms. This also means that this phenomenon can be easily avoided by using the appropriate cleaning or drossing-off fluxes during the treatments, which create powdery dross.

At last, it must be highlighted that the results of this study are specific to the working parameters of the described degassing method (including rotor geometry, crucible size, melt quantity, purging gas flow rate, impeller rotational speed, and length of the treatments). In another experiment, or in the industrial practice where these parameters are different, similar bifilm contents could be reached with rather different treatment lengths and/or treatment numbers. However, from a technological point of view, we can give recommendations regarding the target bifilm and solute hydrogen levels that should be reached during melt treatments, depending on the application of the cast component. Where high structural integrity is needed, such as in structural and safety-critical applications in the automotive and aerospace industries, especially low bifilm and hydrogen content is recommended (such as in the case of the fifth RPT sample shown in Figure 6(a)). This can be achieved by numerous methods: rotary degassing can be combined with flux treatments; filters or sedimentation techniques can be used, as well as the casting technology itself should be optimized for avoiding entrainment defects. ${ }^{[61,62]}$ In this case, the relatively large tendency to shrinkage must be compensated by an appropriate feeding system design. Where high structural integrity is not the main requirement (which is often the case when high pressure die cast (HPDC) components are manufactured with high productivity rates), low bifilm and hydrogen content are not crucial. In this case, the removal of large-sized bifilms (usually originating from the oxide skin of the charge material) and intermediate hydrogen levels are sufficient. This can be achieved by only one treatment. Small-sized bifilms and a controlled amount of solute hydrogen can even lower the tendency to shrinkage porosity formation.

\section{CONCLUSION}

In this study, the effects of multiple rotary degassing treatments conducted with $\mathrm{Ar}$ and $\mathrm{N}_{2}$ purging gases on the bifilm quantity of a liquid aluminum alloy were compared. Based on the experimental results, the following conclusions can be drawn:

- After the first treatment, the application of Ar as a purging gas during consecutive rotary degassing treatments resulted in continuously improving melt quality.

- The application of $\mathrm{N}_{2}$ as a purging gas did not provide significant improvement in melt quality; the bifilm content of the melt was even increased after the melt treatments.

- The negative effect of $\mathrm{N}_{2}$ purging on the melt quality can be partly attributed to the chemical reaction between the purging gas and the liquid alloy. The possible impurities $\left(\mathrm{O}_{2}\right.$ and $\left.\mathrm{H}_{2} \mathrm{O}\right)$ of the applied purging gas also contributed to the degradation of melt quality. 


\section{ACKNOWLEDGMENTS}

Supported by the ÚNKP-21-3 New National Excellence Program of the Ministry for Innovation and Technology from the Source of the National Research, Development and Innovation Fund. The authors thank Árpád Kovács for his assistance in the making of SEM images and EDS analysis.

\section{CONFLICT OF INTEREST}

On behalf of all authors, the corresponding author states that there is no conflict of interest.

\section{FUNDING}

Open access funding provided by University of Miskolc.

\section{OPEN ACCESS}

This article is licensed under a Creative Commons Attribution 4.0 International License, which permits use, sharing, adaptation, distribution and reproduction in any medium or format, as long as you give appropriate credit to the original author(s) and the source, provide a link to the Creative Commons licence, and indicate if changes were made. The images or other third party material in this article are included in the article's Creative Commons licence, unless indicated otherwise in a credit line to the material. If material is not included in the article's Creative Commons licence and your intended use is not permitted by statutory regulation or exceeds the permitted use, you will need to obtain permission directly from the copyright holder. To view a copy of this licence, visit http://creativec ommons.org/licenses/by/4.0/.

\section{REFERENCES}

1. F. Czerwinski: Metall. Mater. Trans. B., 2017, vol. 48B, pp. 367-93. https://doi.org/10.1007/s11663-016-0807-6.

2. M. Jolly: JOM., 2005, vol. 57, pp. 19-28. https://doi.org/10.1007/ s11837-005-0091-4.

3. J. Campbell: Complete Casting Handbook: Metal Casting Processes, Metallurgy Techniques and Design, Elsevier, Amsterdam, 2015.

4. J. Campbell: J. Mater. Sci., 2016, vol. 51, pp. 96-106. https://doi. org/10.1007/s 10853-015-9399-9.

5. J. Campbell: Int. J. Met., 2012, vol. 6, pp. 7-18. https://doi.org/10. 1007/BF03355529.

6. D. Dispinar and J. Campbell: Int. J. Cast Met. Res., 2004, vol. 17, pp. 280-6. https://doi.org/10.1179/136404604225020704.

7. P. Yousefian and M. Tiryakioğlu: Metall. Mater. Trans. A., 2018, vol. 49A, pp. 563-75. https://doi.org/10.1007/s11661-017-4438-6.

8. M. Tiryakioğlu, P. Yousefian, and P.D. Eason: Metall. Mater. Trans. A., 2018, vol. 49A, pp. 5815-22. https://doi.org/10.1007/ s11661-018-4865-z.

9. M.A. El-Sayed, H. Hassanin, and K. Essa: Int. J. Adv. Manuf. Technol., 2016, vol. 86, pp. 1173-9. https://doi.org/10.1007/s0017 0-015-8240-6.
10. A. Samuel, Y. Zedan, H. Doty, V. Songmene, and F.H. Samuel: Adv. Mater. Sci. Eng., 2021, vol. 2021, p. 1921603. https://doi.org/ $10.1155 / 2021 / 1921603$.

11. M. Tiryakioğlu and P. Yousefian: in Encyclopedia of Aluminum and Its Alloys, G.E. Totten, M. Tiryakioğlu, and O. Kessler, eds., Taylor \& Francis, 2018, pp. 1263-9. https://doi.org/10.1201/9781 351045636-140000301.

12. M. Uludağ, R. Çetin, and D. Dispinar: Metall. Mater. Trans. A., 2018, vol. 49A, pp. 1948-61. https://doi.org/10.1007/s11661-0184512-8.

13. M. Tiryakioğlu: Materials., 2020, vol. 13, p. 2019. https://doi.org/ $10.3390 /$ ma13092019.

14. J. Campbell: Materials., 2021, vol. 14, p. 1297. https://doi.org/10. 3390/ma14051297.

15. A.M. Samuel and F.H. Samuel: J. Mater. Sci., 1992, vol. 27, pp. 6533-63. https://doi.org/10.1007/BF01165936.

16. M. Tiryakioğlu: Int. J. Cast Met. Res., 2020, vol. 33, pp. 120-2. https://doi.org/10.1080/13640461.2020.1767838.

17. M. Tiryakioğlu: in Shape Casting, M. Tiryakioğlu, W. Griffiths, and M. Jolly, eds., TMS, 2019, pp. 143-50. https://doi.org/10.10 07/978-3-030-06034-3_14.

18. M. Tiryakioğlu: Int. $\bar{J}$. Cast Met. Res., 2020, vol. 33, pp. 153-6. https://doi.org/10.1080/13640461.2020.1797335.

19. M. Tiryakioğlu: Metall. Mater. Trans. A., 2018, vol. 49A, pp. 5953-5. https://doi.org/10.1007/s11661-018-4969-5.

20. G. Gyarmati, G.Y. Fegyverneki, T. Mende, and M. Tokár: Mater. Charact., 2019, vol. 157, p. 109925. https://doi.org/10.1016/j.ma tchar.2019.109925

21. J. Campbell: The Mechanisms of Metallurgical Failure The Origin of Fracture, Elsevier, Amsterdam, 2020.

22. J. Campbell: in Casting Processes, Z. Abdallah and N. Aldoumani, eds., IntechOpen, 2020. https://doi.org/10.5772/intechopen.93 739.

23. J.E. Gruzleski and B.M. Closset: The Treatment of Liquid Aluminum-Silicon Alloys, American Foundrymen's Society Inc, Schaumburg, 1990, pp. 143-84.

24. G.K. Sigworth: Best Practices in Aluminum Metalcasting, American Foundry Society, Schaumburg, 2014, pp. 59-72.

25. R. Otsuka: in Encyclopedia of Aluminum and Its Alloys, G.E. Totten, M. Tiryakioğlu, and O. Kessler, eds., Taylor \& Francis, 2018, pp. 1698-724. https://doi.org/10.1201/9781351045636-1400 00427.

26. T.A. Engh and T. Pedersen: in Light Metals 1984, J.P. McGeer, ed., TMS, 1984, pp. 218-25.

27. R. Gallo: AFS Trans., 2008, vol. 116, pp. 195-220.

28. M. Mostafaei, M. Ghobadi, G.B. Eisaabadi, M. Uludăg, and M. Tiryakioğlu: Metall. Mater. Trans. B., 2016, vol. 47B, pp. 3469-75. https://doi.org/10.1007/s11663-016-0786-7.

29. V.S. Warke, S. Shankar, and M.M. Makhlouf: J. Mater. Process. Technol., 2005, vol. 168, pp. 119-26. https://doi.org/10.1016/j.jma tprotec.2004.10.017.

30. M. Uludağ, R. Çetin, L. Gemi, and D. Dispinar: J. Mater. Eng. Perform., 2018, vol. 27, pp. 5141-51. https://doi.org/10.1007/s116 65-018-3534-0.

31. M. Uludag and D. Dispinar: Arch. Foundry Eng., 2017, vol. 17, pp. 157-62. https://doi.org/10.1515/afe-2017-0029.

32. D. Dispinar, S. Akhtar, A. Nordmark, M. Di Sabatino, and L. Arnberg: Mater. Sci. Eng. A., 2010, vol. 527, pp. 3719-25. http s://doi.org/10.1016/j.msea.2010.01.088.

33. T. Yamamoto, W. Kato, and S.V. Komarov: Metall. Mater. Trans. B., 2019, vol. 50B, pp. 2547-56. https://doi.org/10.1007/ s11663-019-01681-2.

34. E. Lordan, J. Lazaro-Nebreda, Y. Zhang, and Z. Fan: JOM., 2019, vol. 71, pp. 824-30. https://doi.org/10.1007/s11837-018-318 6-4.

35. C. Lee, T. So, and K. Shin: Acta Metall. Sin., 2016, vol. 29, pp. 638-46. https://doi.org/10.1007/s40195-016-0434-x.

36. J. Lazaro-Nebreda, J.B. Patel, and Z. Fan: J. Mater. Process. Technol., 2021, https://doi.org/10.1016/j.jmatprotec.2021.117146.

37. A. Yorulmaz, E. Erzi, O. Gursoy, and D. Dispinar: Int. J. Cast Met. Res., 2019, vol. 32, pp. 164-70. https://doi.org/10.1080/136 40461.2019.1598684.

38. D. Dispinar and J. Campbell: Mater. Sci. Eng. A., 2011, vol. 528, pp. 3860-5. https://doi.org/10.1016/j.msea.2011.01.084. 
39. G. Gyarmati, G.Y. Fegyverneki, M. Tokár, and T. Mende: Int. J. Met., 2020, vol. 14, pp. 372-80. https://doi.org/10.1007/s40962-020-00428-Z.

40. X. Cao and J. Campbell: in 2nd International Aluminum Casting Technology Symposium, 2002, pp. 135-46.

41. C. Borgonovo and M.M. Makhlouf: Metall. Mater. Trans. A., 2016 , vol. 47A, pp. 5125-35. https://doi.org/10.1007/s11661-016-3665-6.

42. G. Gyarmati, G.Y. Fegyverneki, M. Tokár, and T. Mende: IOP Conf. Ser. Mater. Sci. Eng., 2020, vol. 903, p. 012003. https://doi. org/10.1088/1757-899X/903/1/012003.

43. S. Fox and J. Campbell: Scr. Mater., 2000, vol. 43, pp. 881-6. https://doi.org/10.1016/S1359-6462(00)00506-6.

44. D. Dispinar and J. Campbell: Int. J. Cast Met. Res., 2004, vol. 17, pp. 287-94. https://doi.org/10.1179/136404604225020704.

45. D. Dispinar and J. Campbell: Int. J. Cast Met. Res., 2006, vol. 19, pp. 5-17. https://doi.org/10.1179/136404606225023300.

46. E. Erzi and M. Tiryakioğlu: Int. J. Met., 2020, vol. 14, pp. 999-1004. https://doi.org/10.1007/s40962-020-00414-5.

47. H. Song, L. Zhang, F. Cao, H. Shen, Z. Ning, Y. Huang, X. Zhao, X. Gu, Z. Qiu, and J. Sun: Scr. Mater., 2021, vol. 191, pp. 179-84. https://doi.org/10.1016/j.scriptamat.2020.09.040.

48. S.W. Hudson and D. Apelian: Int. J. Met., 2016, vol. 10, pp. 315-21. https://doi.org/10.1007/s40962-016-0030-x.

49. J. Campbell: Mater. Sci. Technol., 2006, vol. 22, pp. 127-45. h ttps://doi.org/10.1179/174328406X74248.

50. É. Tremblay and B. Maltais: TMS., 2017, vol. 2017, pp. 1475-80. https://doi.org/10.1007/978-3-319-51541-0_176.

51. X. Cao and J. Campbell: Can. Metall. Q., 2005, vol. 44, pp. 435-48. https://doi.org/10.1179/cmq.2005.44.4.435.

52. S.A. Impey, D.J. Stephenson, and J.R. Nicholls: Mater. Sci. Technol., 1988, vol. 4, pp. 1126-32. https://doi.org/10.1179/mst. 1988.4.12.1126.
53. G. Wu, K. Dash, M.L. Galano, and K.A.Q. O'Reilly: Corros. Sci, 2019, vol. 155, pp. 97-108. https://doi.org/10.1016/j.corsci.2019. 04.018 .

54. M.M. Jalilvand, M. Akbarifar, M. Divandari, and H. Saghafian: J. Magnes. Alloy., 2020, vol. 8, pp. 219-30. https://doi.org/10.10 16/j.jma.2019.12.003.

55. A.M. Samuel, E.M. Elgallad, F.H. Samuel, H.W. Doty, and S. Valtierra: Int. J. Met., 2017, vol. 11, pp. 240-54. https://doi.org/10. 1007/s40962-016-0066-y.

56. A.M. Samuel, H.W. Doty, S. Valtierra, and F.H. Samuel: Int. J. Met., 2017, vol. 11, pp. 766-77. https://doi.org/10.1007/s40962016-0122-7.

57. Y. Matsui, M. Morobayashi, and H. Shiomi: Light Metals., 2018, vol. 2018, pp. 885-93. https://doi.org/10.1007/978-3-319-72284-9_ 115.

58. R. Raiszadeh and W.D. Griffiths: Metall. Mater. Trans. B., 2006, vol. 37B, pp. 865-71. https://doi.org/10.1007/BF02735007.

59. R. Raiszadeh and W.D. Griffiths: Metall. Mater. Trans. B., 2008, vol. 39B, pp. 298-303. https://doi.org/10.1007/s11663-008-9142-x.

60. M.A. El-Sayed, H.A.G. Salem, A.Y. Kandeil, and W.D. Griffiths: Metall. Mater. Trans. B., 2014, vol. 45B, pp. 1398-406. https://doi. org/10.1007/s11663-014-0035-x.

61. J. Campbell: Mini Casting Handbook, Aspect Design, 2018. pp. 19-81.

62. G. Gyarmati, G.Y. Fegyverneki, Z. Kéri, D. Molnár, M. Tokár, L. Varga, and T. Mende: Mater. Charact., 2021, vol. 181, p. 111467. https://doi.org/10.1016/j.matchar.2021.111467.

Publisher's Note Springer Nature remains neutral with regard to jurisdictional claims in published maps and institutional affiliations. 